\title{
DYNAMICAL MODELLING OF HYDRAULIC EXCAVATOR CONSIDERED AS A MULTIBODY SYSTEM
}

\author{
Rosen Mitrev, Dragoslav Janošević, Dragan Marinković
}

Original scientific paper

This paper considers the development of a plane multibody mechanical model of a hydraulic excavator simultaneously containing an open kinematic chain and closed loops. The Lagrange multiplier technique is used for modelling of the constrained mechanical systems. This approach is used for working out the dynamic equations of excavator motion in the case of performing transportation and digging operations. The excavator is considered as a rigid body system and detailed governing equations of the mechanical and hydraulic systems are presented. The performed verification and a typical digging task simulation show the applicability of the model for study of the excavator motion simulation. Simulation results of the machine's response are provided. It is shown that the digging process considerably influences the mechanical and hydraulic system parameters. Such models can be used for training simulators, sizing components and system design.

Keywords: hydraulic excavator; Lagrange multiplier; multibody dynamical model

\section{Dinamičko modeliranje hidrauličnog bagera kao sustava sastavljenog od više tijela}

Izvorni znanstveni članak

Rad se bavi razvojem mehaničkog modela hidrauličnog bagera od više tijela koji u isto vrijeme sadrži otvoreni kinematički lanac i zatvorene petlje. Za modeliranje ograničenih mehaničkih sustava primijenjena je tehnika Lagrangeova faktora. Taj se pristup primjenjuje za dobivanje dinamičkih jednadžbi kretanja bagera kod obavljanja prijenosa i operacija kopanja. Bager se smatra sustavom krutog tijela i predstavljaju se detaljne jednadžbe za uređenje mehaničkih i hidrauličnih sustava. Izvršena provjera i simulacija tipičnog kopanja pokazuju primjenjivost sustava za proučavanje simulacije kretanja bagera. Daju se simulacijski rezultati reakcije stroja. Pokazano je da postupak kopanja znatno utječe na parametre mehaničkog i hidrauličkog sustava. Takvi se modeli mogu koristiti za obučavanje simulatora, dimenzioniranje sastavnih dijelova i dizajniranje sustava.

Ključne riječi: dinamički model od više tijela; hidraulični bager; Lagrangeov factor

\section{Introduction}

The hydraulic excavators are widely used in construction, mining and other areas of the modern industry. Their main function is to perform digging operations with consecutive transport of the excavated material to the transport vehicle. A typical excavator (Fig. 1) consists of a traveling body 1 , a swing body 2 and a front digging manipulator 3 by which digging operations are performed. The manipulator consists of a number of moving elements, main of which are the boom $3 \mathrm{a}$, the stick $3 \mathrm{~b}$ and the bucket $3 \mathrm{c}$. Though hydraulic driving systems have some drawbacks, they are extensively used for controlling the excavator links mainly because they can overcome large forces, which originate from the interaction between the bucket and the excavated material. The moving elements of the digging manipulator are controlled by hydraulic cylinders 4, which are connected to the links directly or through transmission linkages 5, see Fig.1.

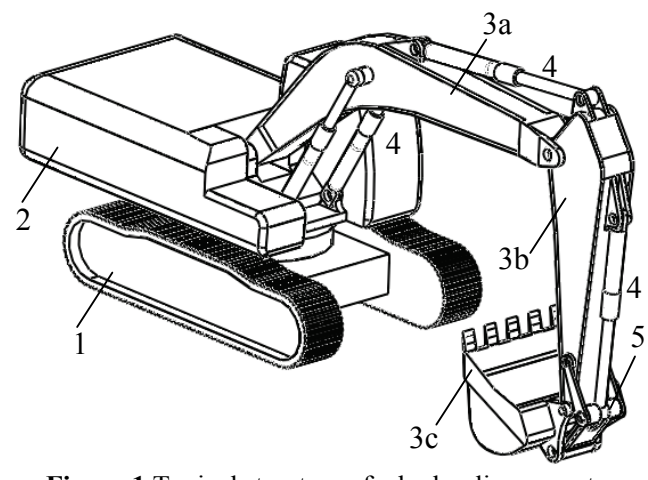

Figure 1 Typical structure of a hydraulic excavator
In the last decades, modelling of the excavator dynamics is a topic of increasing interest for different kind of specialists. Dynamical modelling of the excavators is crucial for designers of the mechanical and hydraulic systems as it enables reduction of prototyping costs and a better insight into the mechanical system behaviour.

Numerous researches have been focused onto the dynamics of various earthmoving, construction and similar machines $[1 \div 4]$. The complexity and the degree of refinement of the developed dynamical models depend on their purpose. The dynamical models of excavators developed by different researchers are intended mainly for the following purposes: 1) control and automation applications $[5 \div 12]$; 2) design of the mechanical and hydraulic systems [2, 13, 14, 15]; 3) study of the interaction with environment $[16 \div 19]$; 4) training simulators $[20] ; 5)$ identification of the excavator parameters $[21,22,23]$.

Typically, the mechanical system of the excavator is modelled as a group of interconnected bodies which undergo large displacements and rotations in the plane or $3 \mathrm{D}$ space. The bodies are connected to each other by different types of joints and are subjected to forces, generated from the hydraulic actuators, gravity and interaction between the bucket and the excavated soil. Usually, the manipulators are modelled as consisting of only open kinematic chain links - boom, stick and bucket $[7,8,17,24,25,26]$ under the assumption that geometry and inertial parameters of these elements have the main contribution to the dynamic behaviour of the mechanical system. Equations of motion are systematically derived in straightforward manner through usage of Denavit- 
Hartenberg convention and application of Lagrange or Newton-Euler formalism.

From the topology point of view, the digging manipulators of different types of excavators are based on the combination of open kinematic chain, formed by the boom, stick and bucket, and closed kinematic chain mechanisms, formed by the hydraulic cylinders and transmission linkages, see Fig. 1 and Fig. 2.

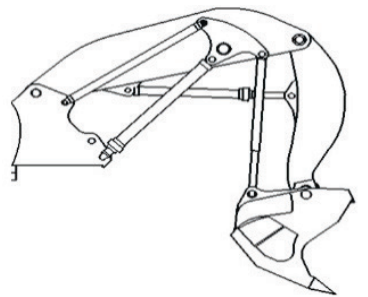

a)

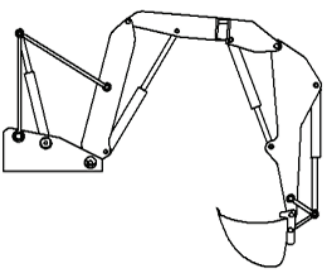

b)
Figure 2 Digging manipulators of different excavators a) Terex O\&K Tripower system; b) Mecalac

The modern enhancement of the computational methods [27] and manufacturing materials [28], also the optimization of the metal structure design [29] leads to light-weight links of the excavator digging manipulator. These points out that the weight of the closed kinematic chain links (primarily the hydraulic cylinders links and transmitting linkages) cannot be ignored compared to the weight of the open kinematic chain links. For example, for excavator CAT330DL, CAD modelling shows that the mass of the hydraulic cylinders and transmitting linkages is about $25 \%$ of the overall mass of the digging manipulator. Sleiman et al. [9] also concluded that inertial parameters of hydraulic actuators of excavator $12 \mathrm{MXT}$ Mecalac should be considered in the dynamical modelling.

One way to increase the precision of the excavator dynamical model is to consider the inertial parameters of the actuators and linkages as constant and to include them in the inertial parameters of the open kinematic chain links as it is made in [5]. This approach, as well as the full neglect of inertial parameters of the closed loops mechanical links, does not ensure the dynamic equivalency of mechanisms and adequate representation of the real structure. A refined dynamical model has to take into account the inertial properties of the elements of the closed loops, formed by the hydraulic cylinders and links of the transmitting mechanisms, i.e. the excavator has to be considered as a multibody system with more than three links - boom, stick and bucket.

There are a few studies to date which deal with the modelling of the excavators and similar hydraulically driven machines as multibody systems. Reference [13] describes a geometric method for formulation of constrained multi-loop linkage dynamics which is applied to a large mining excavator. The domain decomposition method with iteration is proposed and applied to dynamic simulation of hydraulic excavators in [30]. Linjama and Virvalo [31] have presented a low order dynamic model for multilink flexible hydraulic cranes. A mathematical model of large-scale mobile construction manipulator, represented by a coupled system of nonlinear ordinary differential equations and formulated in minimal coordinates, is developed in [32]. Based on Kane dynamic equations, analytical dynamic model for 6 DOF industrial robotic manipulator containing two closed chains and 10 links is developed [33]. Reference [21] investigates the modelling and control of a full-scale unmanned excavator vehicle. The developed model takes into account the kinematics and dynamics of the mobile vehicle and the excavation manipulator. Fox et al. [34] have adopted the multibody approach and DAE formulation of excavator and front loader dynamics and used their own software for simulation of the prescribed trajectories.

A key problem in the dynamic simulation of the excavators is the coupling of the mechanical system and hydraulic drive systems. These subsystems affect each other during digging or transport operations and their simultaneous investigation can give deep understanding of the full system behaviour. One way to model such interaction between subsystems is to analytically formulate the equations of motion of mechanical system and the governing equations of the hydraulic system [35]. These equations are integrated simultaneously in time as a single system of equations or a solution can be obtained by co-simulation in different specialized numerical codes. Hydraulic differential equations are stiff and suitable numerical solvers must be employed. Another widely applied approach for modelling hydro-mechanical systems is the use of multi-domain simulation tools [27, 36].

In the last decades, computer oriented methodology, based on Lagrange multiplier technique is developed and widely used [37]. This efficient modelling technique is suitable for systematic multibody system modelling. Adoption of this approach, combined with the use of modern computer algebra systems, facilitates individual researchers and designers in the development of dynamical models of multibody systems comprising tens of bodies without care about difficulties when performing symbolic and numeric calculations and visualization of results.

According to the defined problems, the main goal of this paper is to develop a plane multibody mechanical model of a hydraulic excavator simultaneously containing an open kinematic chain and closed loops with capabilities for calculation of the excavator dynamical parameters and joint forces during transportation and digging operations.

Below, the Lagrange multiplier technique is used for modelling of the constrained mechanical systems. The excavator is considered as a rigid body system and detailed governing equations of the mechanical and hydraulic systems are presented. The performed verification and a typical digging task simulation demonstrate the applicability of the model in the analysis of the excavator motion.

\section{Mechanical system modelling}

The dynamic simulation of the mechanical systems with closed loops is more difficult than the open kinematic chain. The main difference originates from the fact that the closed loop systems have fewer degrees of freedom than the number of connected bodies. The relative motion of the elements depends on each other and is determined by a solution of loop closure equations. To 
define the configuration of the system unambiguously the number of required coordinates is greater than the number of degrees of freedom.

Reading through the dynamics literature, large variety of methods is available to formulate the excavator dynamics, including the iterative Newton-Euler dynamic formulation, the Lagrangian formulation, Kane's method, and others. Lagrange equations of the first kind are well established in the analytical mechanics and suitable for derivation of equations of the multibody systems with closed loops:

$$
\frac{\mathrm{d}}{\mathrm{d} t} \frac{\partial L}{\partial \dot{q}_{e}}-\frac{\partial L}{\partial q_{e}}+\sum_{f=1}^{m} \lambda_{f} \frac{\partial \phi_{f}}{\partial q_{e}}=Q_{e} \quad e=1,2, \ldots, n
$$

where $L=T-U$ is the Lagrangian function of the mechanical system; $T$ is the kinetic energy of the system; $U$ is the potential energy of the system; $q_{e}, e=1,2, \ldots, n$ is the set of $n$ dependent coordinates; $Q_{e}$ are the generalized externally applied forces, acting along the generalized coordinates. In the case of body centroidal coordinate system this vector consists of terms originating from springs, dampers and actuators forces; $\phi_{f}, f=1,2, \ldots, m$ is a set of independent constraint equations; $\lambda_{f}$ are called Lagrange multipliers.

Eq. (1) represents $n$ equations with $(n+m)$ unknowns. In order to have the number of equations sufficient to obtain the solution, it is necessary to provide additional $m$ equations. The obvious choice is to use the algebraic constraints (2) which along with Eqs. (1) constitute a set of differential algebraic equations (DAE's) of index 3:

$$
\phi_{f}(q, t)=0, f=1,2, \ldots, m
$$

By writing Eqs. (1) and Eqs. (2) together, one obtains a system of DAE's consisting of $(n+m)$ equations with $(n+m)$ unknowns. This approach leads to a large system of loosely coupled equations that can be solved for the generalized coordinates and Lagrange multipliers. The vector of Lagrange multipliers is used to determine the generalized reaction forces.

For the purpose of the present study, the hydraulic excavator mechanical system is defined as a set of rigid bodies, connected by rotational or translational pairs. All bodies can move relative to each other in the plane. Each body has a mass $m_{k}$ and mass moment of inertia with respect to its mass centre $J_{k}$. In order to specify the position of the excavator, it is necessary to define coordinates that specify the location of the mass centre of each body and points at which the bodies are interconnected. Fig. 3 shows the geometrical relationship that exists between the global and local representations of the points and vectors on the body. The $\left\{x_{0} y_{0}\right\}$ is the global reference frame and the origin of the body fixed coordinate system (c.s.) $\left\{x_{k} y_{k}\right\}$ is placed at the centre of mass of body $k$. The position and orientation of body $k$ are specified by the position vector $\boldsymbol{R}^{k}$ and the angle of rotation $\varphi^{k}$ of the $x_{k}$ axis of the body fixed local c.s $\left\{x_{k} y_{k}\right\}$ relative to the $x_{0}$ axis of the global c.s. The angle $\varphi^{k}$ is considered as positive if the rotation of the $x_{k}$ axis from the positive $x_{0}$ axis is counter clockwise. A fixed point $\mathrm{P}$ on body $k$ can be located from the origin of the local c.s. $\left\{x_{k} y_{k}\right\}$ by the vector $\overline{\boldsymbol{u}}_{\mathrm{P}}^{k}$ and from the origin of the global c.s. $\left\{x_{0} y_{0}\right\}$ by the vector $r_{\mathrm{P}}^{k}$, see Fig. 3 .

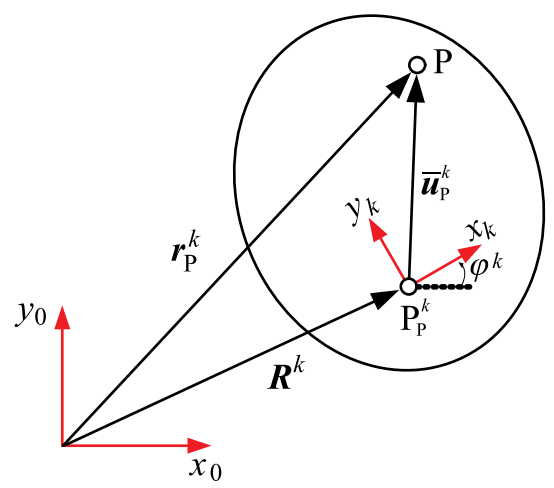

Figure 3 Position and orientation of a body relative to the global reference frame

Vectors $\boldsymbol{R}^{k}$ and $\boldsymbol{r}_{\mathrm{P}}^{k}$ have components that vary with time:

$$
\boldsymbol{R}^{k}=\left[\begin{array}{c}
x^{k}(t) \\
y^{k}(t)
\end{array}\right], \quad \boldsymbol{r}_{\mathrm{P}}^{k}=\left[\begin{array}{c}
x_{\mathrm{P}}^{k}(t) \\
y_{\mathrm{P}}^{k}(t)
\end{array}\right]
$$

One can write the following relationship about the position of an arbitrary point $\mathrm{P}$ measured with respect to the global c.s.:

$$
\boldsymbol{r}_{\mathrm{P}}^{k}=\boldsymbol{R}^{k}+\boldsymbol{A}^{k} \overline{\boldsymbol{u}}_{\mathrm{P}}^{k}
$$

where $A^{k}$ is the rotation matrix of the body $k$ :

$$
\boldsymbol{A}^{k}=\left[\begin{array}{cc}
\cos \varphi^{k} & -\sin \varphi^{k} \\
\sin \varphi^{k} & \cos \varphi^{k}
\end{array}\right]
$$

The position of the point $\mathrm{P}$ is represented in the local coordinate system by two constant coordinates:

$$
\overline{\boldsymbol{u}}_{\mathrm{P}}^{k}=\left[\begin{array}{ll}
\bar{x}_{\mathrm{P}}^{k} & \bar{y}_{\mathrm{P}}^{k}
\end{array}\right]^{\mathrm{T}}
$$

In summary, the position and orientation of the $\kappa^{\text {th }}$ body in the $x y$ plane can be represented by three generalized coordinates $x^{k}, y^{k}$ and $\varphi^{k}$ :

$\boldsymbol{q}^{k}=\left[x^{k}, y^{k}, \varphi^{k}\right]^{\mathrm{T}}$

For a system of $k$ planar bodies, the vector of generalized coordinates is a $3 k$ vector $\boldsymbol{q}$ :

$$
\boldsymbol{q}=\left[x^{1}, y^{1}, \varphi^{1}, \ldots, x^{k}, y^{k}, \varphi^{k}\right]^{\mathrm{T}}
$$

Since the considered planar model of the excavator consists of 12 bodies (see Fig. 4), the vector of generalized coordinates of the entire mechanical system is:

$$
\boldsymbol{q}=\left[x^{1}, y^{1}, \varphi^{1}, x^{2}, y^{2}, \varphi^{2}, \ldots, x^{12}, y^{12}, \varphi^{12}\right]^{\mathrm{T}}
$$


In terms of the generalized coordinates, kinetic and potential energies of the mechanical system are represented by Eq. (10) and Eq. (11) respectively

$$
\begin{aligned}
& T=\sum_{k=1}^{12}\left(\frac{1}{2} m_{k}\left(\left(\dot{x}^{k}\right)^{2}+\left(\dot{y}^{k}\right)^{2}\right)+\frac{1}{2} J_{k}\left(\dot{\varphi}^{k}\right)^{2}\right) \\
& U=\sum_{k=1}^{12} m_{k} g y^{k}
\end{aligned}
$$

where $g$ is the Earth gravitational acceleration.

\subsection{Constraint equations}

Schematic representation of the considered excavator mechanical system is shown in Fig. 4.
The presented excavator model (Fig. 4) comprises the base body 12 (which consist of traveling and swing bodies, represented as a single body) and 11 elements of the front digging manipulator -3 bodies from the open kinematic chain (boom, stick and bucket) and 8 bodies from the closed kinematic chains (hydraulic cylinders and fourbar parts). Fig. 4 shows the global reference frame, located at the point $\mathrm{A}$ and the body fixed coordinate frames $\left\{x_{1} y_{1}\right\},\left\{x_{2} y_{2}\right\}$, etc. By means of Fig. 4 one can identify the kinematic pairs which impose constraints on the relative motion between the links. In a whole, the mechanical model of the excavator consists of 12 bodies which are connected with each other by 12 revolute and 3 translational joints. In addition, the base body is connected to the ground by springs and dampers RS, QU and QT, which represent the compliant tires, caterpillar chains or hydraulic support.

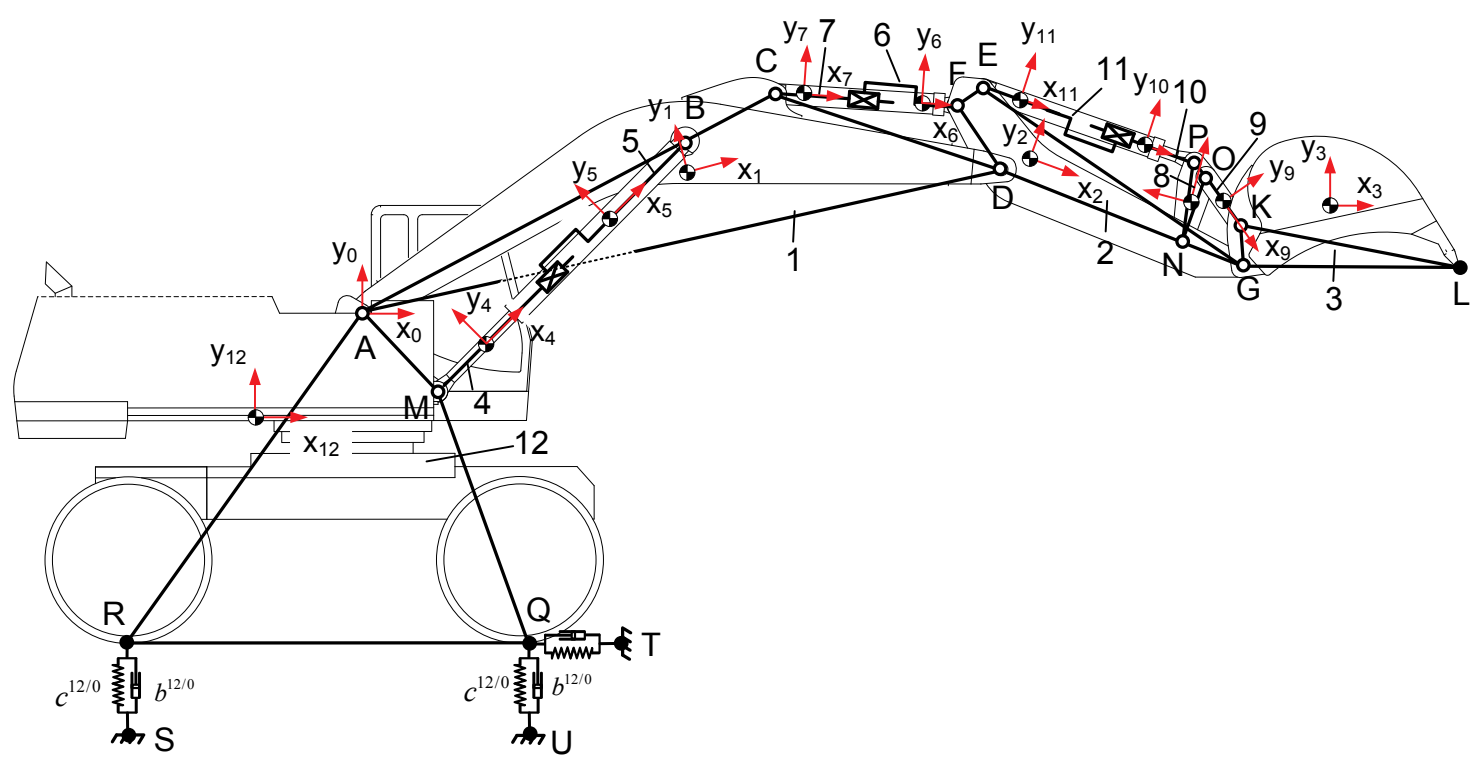

Figure 4 Multibody model of a hydraulic excavator

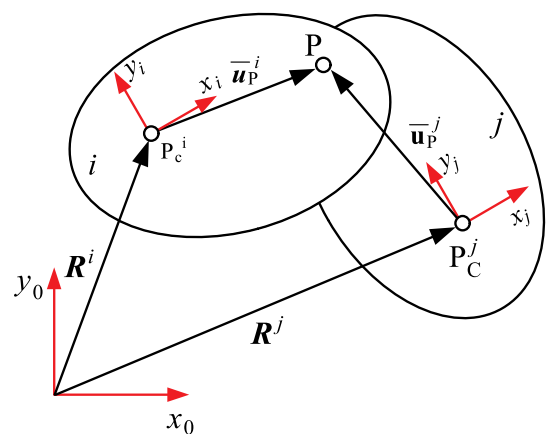

Figure 5 Schematic representation of two bodies, connected by a revolute joint

Mathematically, constraints between the bodies are expressed by constraint equations. In order to find the constraint equations for a revolute joint, let us consider the schematic representation of a revolute joint connecting links $i$ and $j$ as shown in Fig. 5. From the figure it is clear that the position vector of the joint $P$ as defined using the absolute coordinates of body $i$ must be equal to the position vector of the same point as defined in terms of the absolute coordinates of body $j$
$\boldsymbol{R}^{i}+\boldsymbol{A}^{i} \overline{\boldsymbol{u}}_{\mathrm{P}}^{i}-\boldsymbol{R}^{j}-\boldsymbol{A}^{j} \overline{\boldsymbol{u}}_{\mathrm{P}}^{j}=\boldsymbol{0}$

which yields two scalar equations (for $x$ and $y$ axes):

$$
\begin{aligned}
& x^{i}+\bar{x}_{\mathrm{P}}^{i} \cos \varphi^{i}-\bar{y}_{\mathrm{P}}^{i} \sin \varphi^{i}-x^{j}-\bar{x}_{\mathrm{P}}^{j} \cos \varphi^{j}+\bar{y}_{\mathrm{P}}^{j} \sin \varphi^{j}=0(13) \\
& y^{i}+\bar{x}_{\mathrm{P}}^{i} \sin \varphi^{i}+\bar{y}_{\mathrm{P}}^{i} \cos \varphi^{i}-y^{j}-\bar{x}_{\mathrm{P}}^{j} \sin \varphi^{j}-\bar{y}_{\mathrm{P}}^{j} \cos \varphi^{j}=0
\end{aligned}
$$

The hydraulic cylinders are represented as consisting of two elements - cylinder tube $i$ and piston with piston $\operatorname{rod} j$. These elements are restricted in motion with respect to each other by means of a translational pair and can be connected to other links by a revolute joint. Origins of the local coordinate systems are at the centres of mass of the links $\mathrm{P}_{\mathrm{C}}^{i}$ and $\mathrm{P}_{\mathrm{C}}^{j}$, which lie on the longitudinal axis of the cylinder. Each link is characterized by geometrical parameters, mass and mass moment of inertia with respect to its centre of mass. Fig. 6 shows a schematic representation of a translational joint between links $i$ and $j$ of the hydraulic cylinder. The line of translation of the joint coincides with the longitudinal axis of the cylinder. 


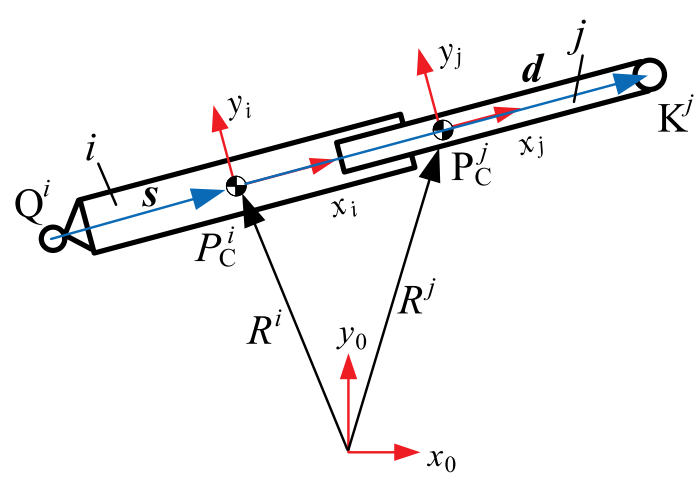

Figure 6 Schematic representation of a hydraulic cylinder

A constraint is required to eliminate the relative translation between the links in a direction perpendicular to the line of translation. To formulate this constraint, the two vectors $\boldsymbol{s}$ and $\boldsymbol{d}$ shown in Fig. 6 must remain parallel. It is convenient to define these vectors by locating three reference points: the end points $\mathrm{Q}^{i}$ and $\mathrm{K}^{j}$ of the cylinder and an additional point $\mathrm{P}_{\mathrm{C}}^{i}$ which lies on the line of translation:

$\boldsymbol{s}=\left[\begin{array}{c}x^{i}-x_{\mathrm{Q}}^{i} \\ y^{i}-y_{\mathrm{Q}}^{i}\end{array}\right], \boldsymbol{d}=\left[\begin{array}{c}x_{\mathrm{K}}^{j}-x^{i} \\ y_{\mathrm{K}}^{j}-y^{i}\end{array}\right]$

The first constraint equation of the translational pair follows from the fact that the vector product of the two parallel vectors is zero

$\boldsymbol{s} \times \boldsymbol{d}=\mathbf{0}$

which is equivalent to:

$\left(x^{i}-x_{\mathrm{Q}}^{i}\right)\left(y_{\mathrm{K}}^{j}-y^{i}\right)-\left(x_{\mathrm{K}}^{j}-x^{i}\right)\left(y^{i}-y_{\mathrm{Q}}^{i}\right)=0$

where

$$
\begin{aligned}
\boldsymbol{r}_{\mathrm{Q}}^{i} & =\boldsymbol{R}^{i}+\boldsymbol{A}^{i} \overline{\boldsymbol{u}}_{\mathrm{Q}}^{i} \\
\boldsymbol{r}_{\mathrm{K}}^{j} & =\boldsymbol{R}^{j}+\boldsymbol{A}^{j} \overline{\boldsymbol{u}}_{\mathrm{K}}^{j} \\
\overline{\boldsymbol{u}}_{\mathrm{Q}}^{i} & =\left[\begin{array}{ll}
\bar{x}_{\mathrm{Q}}^{i} & 0
\end{array}\right]^{\mathrm{T}}, \overline{\boldsymbol{u}}_{\mathrm{K}}^{j}=\left[\begin{array}{ll}
\bar{x}_{\mathrm{K}}^{j} & 0
\end{array}\right]^{\mathrm{T}}
\end{aligned}
$$

Since the $x$-axes of the coordinate systems coincide with the line of translation of the pair, a constraint equation that eliminates the relative rotation between the two bodies can be written as:

$$
\varphi^{i}-\varphi^{j}=0
$$

The same equations are used in the case of translational joint between links, for example for modelling of excavator telescopic stick.

\subsection{Modelling of the hydraulic cylinder force and compliant supporting structure}

When a hydraulic cylinder extends or retracts, it moves a link and exerts a force on it. The force, applied by the hydraulic cylinder consisting of bodies $i$ and $j$ due to the action of the hydraulic pressures onto the piston areas is

$$
F_{p}^{i / j}=p_{1} A_{1}-p_{2} A_{2}
$$

where $A_{1}$ and $A_{2}$ are the actuator piston area and the actuator rod area, respectively.

Because of considerable friction forces that exist in the excavator hydraulic cylinders [38], the resistive force $F_{r}$ which opposes movements of the piston consists of a linear viscous term $F_{v}^{i / j}=\left(b^{i / j}\right) j^{i / j}$ and a Coulomb friction term $F_{f}^{i / j}=\operatorname{sign}\left(l^{i / j}\right) F_{c}^{i / j}$ :

$$
F_{r}^{i / j}=F_{v}^{i / j}+F_{f}^{i / j}
$$

where $F_{c}^{i / j}$ denotes the magnitude of the Coulomb friction force between the seals and the cylinder tube; $b^{i / j}$ is a viscous friction coefficient; $j^{i / j}$ is the velocity of the distance change between points $\mathrm{P}_{\mathrm{C}}^{i}$ and $\mathrm{P}_{\mathrm{C}}^{j}$. Thus, the total force generated by the hydraulic cylinder is directed along the longitudinal axis of the cylinder and has a magnitude $F_{h c}^{i / j}$ :

$F_{h c}^{i / j}=F_{p}^{i / j}-F_{r}^{i / j}-F_{h s}^{i / j}$

To restrict the movement of the piston in the limits of the stroke, in Eq. (24) a force $F_{h s}^{i / j}$ is introduced which imitates hard stops at the ends of the cylinder stroke:

$$
F_{h s}^{i / j}=\mid \begin{aligned}
& c_{h s}^{i / j}\left(l^{i / j}-l_{0}^{i / j}-L^{i / j}\right) \text { if }\left(l^{i / j}-l_{0}^{i / j}-L^{i / j}\right)>0 \\
& 0 \text { if } 0 \leq\left(l^{i / j}-l_{0}^{i / j}\right) \leq L^{i / j} \\
& -c_{h s}^{i / j}\left(l^{i / j}-l_{0}^{i / j}\right) \text { if }\left(l^{i / j}-l_{0}^{i / j}\right)<0
\end{aligned}
$$

where by $c_{h s}^{i / j}$ is denoted the contact stiffness at the ends of the cylinder stroke; $L^{i / j}$ is the stroke of the cylinder.

When the controlling valve of the hydraulic circuit is in its spring cantered position, the cylinder is locked. In this case the cylinder acts as a supporting structure with constant length and behaves like an oil spring due to the compliance of the hydraulic oil. It dissipates the energy due to the viscous and friction forces in the cylinder. Resistant force $F_{r}^{i / j}$, which opposes movements of the links, consists of a linear viscous term, Coulomb friction term and spring force $F_{c}^{i / j}=c^{i / j}\left(l^{i / j}-l_{0}^{i / j}\right)$ :

$$
F_{r}^{i / j}=F_{v}^{i / j}+F_{f}^{i / j}+F_{c}^{i / j}
$$

where $c^{i / j}$ is the oil spring stiffness constant; $l^{i / j}$ is the current spring length and $l_{0}^{i / j}$ is the undeformed spring length. In this case, the force in the hydraulic cylinder is

$F_{h c}^{i / j}=-F_{r}^{i / j}$ 
The base body of the excavator is in contact with the ground through the supporting structure which can comprise compliant tires, caterpillar chains or hydraulic supports. If the deformation of the supporting structure is small, one can consider that the contact of the base body with the ground is achieved through linear springs and dampers (see Fig. 4) and Eq. (26) with suitable stiffness and damping coefficients is used. The compliance of the supporting structure is represented by springs and dampers in $x$ and $y$ directions.

The current spring or hydraulic cylinder length $l^{i / j}$ is calculated as

$l^{i / j}=\left|\boldsymbol{r}_{\mathrm{P}}^{i / j}\right|=\sqrt{\left(\boldsymbol{r}_{\mathrm{P}}^{i / j}\right)^{\mathrm{T}} \boldsymbol{r}_{\mathrm{P}}^{i / j}}$

and $r_{\mathrm{P}}^{i / j}$ is the position vector of point $\mathrm{P}^{i}$ with respect to point $\mathrm{P}^{j}$, i.e. $\boldsymbol{r}_{\mathrm{P}}^{i / j}=\boldsymbol{r}_{\mathrm{P}}^{i}-\boldsymbol{r}_{\mathrm{P}}^{j}=\boldsymbol{R}^{i}+\boldsymbol{A}^{i} \overline{\boldsymbol{u}}_{\mathrm{P}}^{i}-\boldsymbol{R}^{j}-\boldsymbol{A}^{j} \overline{\boldsymbol{u}}_{\mathrm{P}}^{j}$.

Let us use $\hat{\boldsymbol{r}}_{\mathrm{P}}^{i / j}=\left(\boldsymbol{r}_{\mathrm{P}}^{i / j}\right) / l^{i j}$ to denote a unit vector along the line of action of the force $F_{h c}^{i / j}$. The velocity $i^{i / j}$ of the change of distance between points $\mathrm{P}_{\mathrm{C}}^{i}$ and $\mathrm{P}_{\mathrm{C}}^{j}$ is obtained through differentiation of Eq. (28):

$i^{i / j}=\frac{\left(\boldsymbol{r}_{\mathrm{P}}^{i / j}\right)^{\mathrm{T}} \dot{\boldsymbol{r}}_{\mathrm{P}}^{i / j}}{l^{i / j}}$

where

$$
\dot{\boldsymbol{r}}_{\mathrm{P}}^{i / j}=\dot{\boldsymbol{R}}^{i}+\dot{\varphi}^{i} \boldsymbol{A}_{\phi}^{i} \overline{\boldsymbol{u}}_{\mathrm{P}}^{i}-\dot{\boldsymbol{R}}^{j}-\dot{\varphi}^{j} \boldsymbol{A}_{\varphi}^{j} \overline{\boldsymbol{u}}_{\mathrm{P}}^{j}
$$

where $\boldsymbol{A}_{\varphi}^{i(j)}$ denotes the first derivative of the rotation matrix (5)

$$
\boldsymbol{A}_{\varphi}^{i(j)}=\left[\begin{array}{cc}
-\sin \varphi^{i(j)} & -\cos \varphi^{i(j)} \\
\cos \varphi^{i(j)} & -\sin \varphi^{i(j)}
\end{array}\right]
$$

The force acting along the cylinder axis is reduced to the centre of mass of the body $i$ (see Fig. 6) yielding the generalized force components $Q_{h c}^{i X}$ and $Q_{h c}^{i Y}$ :

$$
\boldsymbol{Q}_{h c}^{i}=-F_{h c}^{i / j}[\boldsymbol{I}] \hat{r}_{\mathrm{P}}^{i / j}=\left[\begin{array}{l}
Q_{h c}^{i X} \\
Q_{h c}^{i Y}
\end{array}\right]
$$

The same applied to body $j$ gives:

$$
\boldsymbol{Q}_{h c}^{j}=F_{h c}^{i / j}[\boldsymbol{I}] \hat{r}_{\mathrm{P}}^{i / j}=\left[\begin{array}{c}
Q_{h c}^{j X} \\
Q_{h c}^{j Y}
\end{array}\right]
$$

where $\boldsymbol{I}$ is the 2 by 2 identity matrix. Note that the generalized moment is zero because the force $F_{h c}^{i / j}$ acts along the cylinder axis and passes through the origin of the link local coordinate system.

Since the spring and dampers, which represent the tires or caterpillar chains, generally do not pass through the origin of the local coordinate system (Fig. 7), the generalized moment has a value different from zero. In this case the vector of generalized forces and moments is in the form (34) and (35).

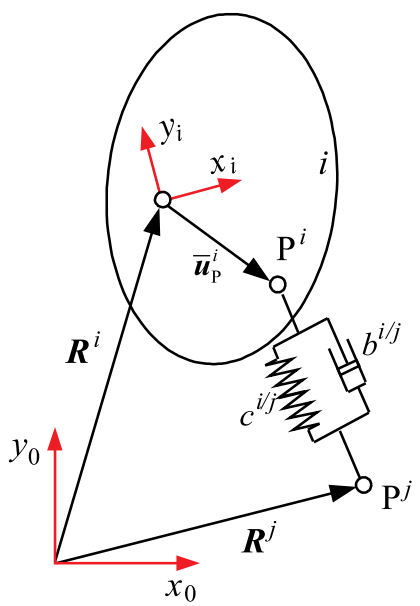

Figure 7 Schematic representation of the base body

$$
\begin{gathered}
\boldsymbol{Q}_{h c}^{i}=-F_{h c}^{i / j}\left[\begin{array}{c}
\boldsymbol{I} \\
\overline{\boldsymbol{u}}_{\mathrm{P}}^{i} \boldsymbol{A}_{\varphi}^{i}
\end{array}\right] \hat{\boldsymbol{r}}_{\mathrm{P}}^{i / j}=\left[\begin{array}{l}
Q_{h c}^{i X} \\
Q_{h c}^{i Y} \\
Q_{h c}^{i \varphi}
\end{array}\right] \\
\boldsymbol{Q}_{h c}^{j}=F_{h c}^{i / j}\left[\begin{array}{c}
\boldsymbol{I} \\
\overline{\boldsymbol{u}}_{\mathrm{P}}^{j^{T}} \boldsymbol{A}_{\varphi}^{j^{T}}
\end{array}\right] \hat{\boldsymbol{r}}_{\mathrm{P}}^{i / j}=\left[\begin{array}{l}
Q_{h c}^{j X} \\
Q_{h c}^{j Y} \\
Q_{h c}^{j \varphi}
\end{array}\right]
\end{gathered}
$$

\subsection{Modelling of the resistant force due to the soil-bucket interaction}

The interaction between the bucket and the excavated soil during digging operations is a problem that is not fully cleared-up in the literature, primarily due to its complexity. Different models have been suggested and are used to determine the resistant digging forces [39, 40, 41]. A widely used practice-oriented approach is to assume that excavated soil exerts a resistive force $P_{d}$ which is applied to the bucket tip at point T, see Fig. 8 . This resistant force is computed as a sum of the resistant forces from cutting the soil, friction between the bucket and soil and filling of the bucket [40]. The tangential component (along line $\mathrm{t}-\mathrm{t}$ ) of the digging force $P_{d}^{t}$ is computed according to the following approximate relation that was experimentally confirmed:

$$
P_{d}^{t}=k w h
$$

where $h$ is the thickness of the cut slice of soil, $w$ is the width of the bucket and $k$ is the specific digging resistance, which includes all three mentioned resistances. Its values are determined experimentally and, for example, are between 200 and $300 \mathrm{kPa}$ for wet clay.

The normal component of the soil resistance is calculated as

$P_{d}^{n}=\psi P_{d}^{t}$ 
where $\psi=0.1-0.45$ is a coefficient which depends on many factors of which the main ones are: the digging angle, digging conditions, type of the soil and the wear of cutting edge. Taking into account Eq. (36) and Eq. (37), the magnitude of the digging force $P_{\mathrm{d}}$ is computed as:

$$
P_{\mathrm{d}}=k w h \sqrt{1+\psi^{2}}
$$

The digging force has variable value because of the variable thickness $h$ of the cut slice along the digging trajectory d-d, see Fig. 8. Additionally, the experimental research shows that the magnitude of the digging force has random oscillatory character, caused by periodic soil failures during forward movement of the bucket [42].

The vector of the generalized forces $\boldsymbol{Q}_{\mathrm{d}}^{3}$ applied to the bucket's (body 3 ) centre of mass due to the digging force is computed as

$$
\boldsymbol{Q}_{\mathrm{d}}^{3}=\left[\begin{array}{c}
\boldsymbol{A}^{3} \\
\overline{\boldsymbol{u}}_{\mathrm{T}}^{3^{T}} \boldsymbol{A}_{\varphi}^{3^{\mathrm{T}}} \boldsymbol{A}^{3}
\end{array}\right] \boldsymbol{P}_{\mathrm{d}}^{3}
$$

where $\boldsymbol{P}_{\mathrm{d}}^{3}$ is the vector of the digging force components, projected onto the c.s. $\left\{x_{3} y_{3}\right\}$ axes

$$
\boldsymbol{P}_{\mathrm{d}}^{3}=\left[\begin{array}{l}
P_{\mathrm{d}} \cos \gamma \\
P_{\mathrm{d}} \sin \gamma
\end{array}\right]
$$

where $\gamma$ is the angle between the axis $x_{3}$ and the digging force direction.

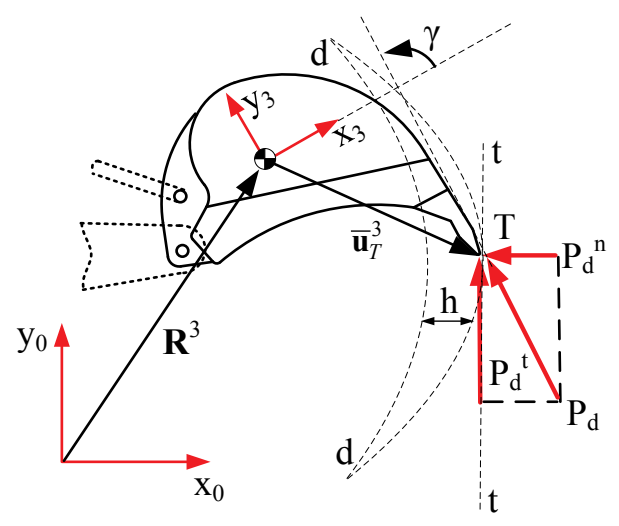

Figure 8 Digging force and loading of the bucket

\section{Hydraulic system modelling}

The typical digging process is conducted by the consecutive motions of the stick and the bucket, which are driven by high pressure hydraulic cylinders. Each cylinder is a part of an independent hydraulic circuit, which is driven by its own hydraulic pump. The pumps are driven by a single engine. The extension or retraction of the single hydraulic cylinder is controlled by a symmetric zero-lapped four-way spool valve. The flow to the cylinder is controlled by the position of the valve spool. Fig. 9 shows a fragment of the simplified schematic of the hydraulic circuit for driving the stick and bucket cylinders.

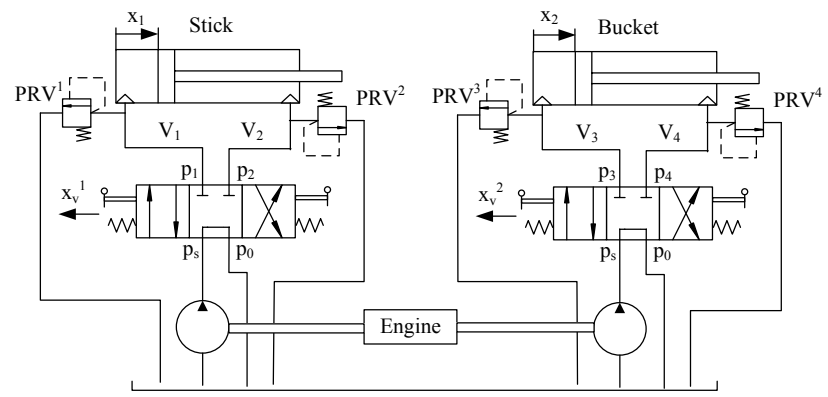

Figure 9 Fragment of the hydraulic circuit and parameters used in the modelling

When the four-way valve is in its spring cantered position, the cylinder is hydraulically locked and the pump flows into the tank. In this case, if a force is applied to the rod, cylinder behaves like an oil spring. When the four-way valve is actuated into the flow path configuration of the left envelope, the cylinder is extended against the force load. When the four-way valve is actuated in the right envelope configuration, the cylinder retracts and the oil from the piston chamber flows into reservoir. To capture the main dynamic effects in the hydraulic cylinder chambers, a simplified dynamical model of the hydraulic circuit is presented.

Since the hydraulic fluid is compressible, it is necessary to consider its effect on the overall dynamic performance of the excavator. The problem of the linear hydraulic actuator modelling is well described in the standard textbooks [43]. Analytical model of the hydraulic system includes orifice flow equations and fluid compressibility equations for the oil volumes.

The flow through the four-way valve is a nonlinear function of the pressure drop across the valve orifices and of the orifice size. The flow through the valve orifices (for turbulent flow) will be introduced as $Q_{1}$ (from the pump to the left chamber of the stick hydraulic cylinder) and $Q_{2}$ (from the right chamber of the stick hydraulic cylinder to the tank):

$$
\begin{aligned}
& Q_{1}=C_{d} w x_{v}^{1}(t) \sqrt{\frac{2\left|p_{s}-p_{1}\right|}{\rho}} \operatorname{sign}\left(p_{s}-p_{1}\right) \\
& Q_{2}=C_{d} w x_{v}^{1}(t) \sqrt{\frac{2\left|p_{2}-p_{0}\right|}{\rho}} \operatorname{sign}\left(p_{2}-p_{0}\right)
\end{aligned}
$$

where $C_{d}$ denotes the orifice discharge coefficient; $w$ is the valve area gradient; $x_{v}^{1}(t)$ is the valve opening as a function of time; $\rho$ is the oil density; $p_{s}$ is the supply pressure; $p_{0}$ is the drain pressure; $p_{1}$ and $p_{2}$ are the pressures in the left and in the right chambers of the stick cylinder respectively. Displacement of the valve spool from the central position creates a pressure difference across the hydraulic cylinder, and the resulting fluid flow causes a movement of the piston.

Important parts of the excavator hydraulic circuit are pressure relief valves $P R V^{1}-P R V^{4}$. They should prevent excessive increase of pressure in the hydraulic cylinder chambers, caused by the inertia loads and increased resistant forces during digging. If the dynamics of the $P R V$ valves is neglected, then the passing flow through 
the valves is described by the following piecewise defined function:

$$
Q_{P R V}^{k}=\mid \begin{gathered}
k_{\mathrm{v}}\left(p_{k}-p_{\mathrm{cr}}\right), \text { if } p_{k}-p_{\mathrm{cr}}>0 \\
0, \text { if } p_{k}-p_{\mathrm{cr}} \leq 0
\end{gathered}, \quad k=1 \ldots 4
$$

where $p_{\mathrm{cr}}$ is the relief valve cracking pressure; $Q_{P R V}^{k}$ is the flow, passing through the $P R V^{k} ; k_{\mathrm{v}}$ is the slope coefficient of the valve static characteristic. Typically, for the hydraulic excavators the cracking pressure of the $P R V$ is set to be $25 \%$ over the rated pressure in the hydraulic circuit.

The continuity equation of the compressible oil, which originates from the mass conservation law, is given as follows:

$$
\Sigma Q_{\text {in }}-\Sigma Q_{\text {out }}=\frac{\mathrm{d} V}{\mathrm{~d} t}+\frac{V}{\beta} \frac{\mathrm{d} P}{\mathrm{~d} t}
$$

In Eq. (44) $V$ is the initial volume of liquid subjected to compression, $\mathrm{d} V$ and $\mathrm{d} P$ are the changes in pressure and volume, $\Sigma Q_{\text {in }}$ is the total input flow of the fluid, and $\Sigma Q_{\text {out }}$ is the total output flow of the fluid, $\beta$ is the bulk modulus. Using the continuity principle and taking into account the fluid compressibility, one can write expressions for the left and right chambers pressure:

$$
\begin{aligned}
& \dot{p}_{1}=\left(\frac{\beta}{V_{1}+A_{1} x_{1}}\right)\left(Q_{1}-A_{1} \dot{x}_{1}-Q_{P R V}^{1}\right) \\
& \dot{p}_{2}=\left(\frac{\beta}{V_{2}+A_{2}\left(l_{1}-x_{1}\right)}\right)\left(A_{2} \dot{x}_{1}-Q_{2}-Q_{P R V}^{2}\right)
\end{aligned}
$$

where $V_{1}$ and $V_{2}$ denote the constant oil volumes in the hydraulic cylinder chambers and connecting hoses; $x_{1}$ is the piston displacement; $l_{1}$ is the stroke of the piston.

Similar equations can be written for the bucket hydraulic circuit. Also, it is considered that: 1) the leak flows of the valve and hydraulic cylinder are negligible; 2) the hydraulic pump is modelled as a constant pressure source, independent of the fluid flow.

\section{Governing equations of the multibody system}

Taking into account Lagrange equations (1), expressions for the kinetic and potential energies, respectively Eqs. $(10) \div(11)$, constraint equations for the rotational Eq. (13) and Eq.(14), the translational Eq. (17) and Eq. (21) pairs, expressions for the generalized digging force Eq. (39) and expressions for the generalized forces from the hydraulic cylinders Eq. (32), Eq. (33) and spring-damper elements Eq. (34), Eq. (35), one can generate equations of motion of the multibody system, shown in Fig. 4. The system of equations which describes the motion of the excavator elements consists of:

1) 36 differential equations of second order - one equation for every generalized coordinate - Eq. (9);

2) 30 constraint equations - 2 equations for every of 12 rotational joints and two for every of 3 translational joints;
3) 6 hydraulic equations of the first order - two equations for the pressures in the chambers of the boom, stick and bucket hydraulic cylinders.

This system of DAE equations of index 3 can be solved by well-known specialized numerical solvers as DASSL, IDA or other, implemented in different computing environments. More practical approach is to solve system of equations as ODE's. To do this one must obtain the acceleration kinematic equations by differentiating Eqs. (2) twice with respect to time:

$$
\ddot{\phi}_{f}=0
$$

Since the derivatives $\partial \phi_{f} / \partial q_{e}$ are already computed during the derivation of Lagrange Eqs. (1), the following formula is used to compute $\ddot{\phi}_{f}$ :

$$
\ddot{\phi}_{f}=\sum_{e=1}^{n} \frac{\partial \phi_{f}}{\partial q_{e}} \ddot{q}_{e}+\sum_{e=1}^{n} \frac{\mathrm{d}}{\mathrm{d} t}\left(\frac{\partial \phi_{f}}{\partial q_{e}}\right) \dot{q}_{e}
$$

Since acceleration constraints are used, the simultaneous solution of Eqs. (1) and Eqs. (2) does not guarantee that the coordinate and velocity constraints are not violated as the integration of equations progresses. A method by Baumgarte is introduced [37] to control the constraint violation, which ensures asymptotic stability of the system. This stabilization method modifies the acceleration constraints by adding two feedback terms and replaces Eq. (47) by Eq. (49):

$\phi_{f}+2 \alpha \dot{\phi}_{f}+\beta^{2} \phi_{f}=0$

where $\alpha$ and $\beta$ are positive constants, chosen for sufficient fast decrease of the errors.

A generated set of equations containing 36 second order differential equations, 30 modified acceleration constraint equations and 6 hydraulic equations is represented in a matrix form as a system of first order differential equations and solved for the state vector $\dot{\boldsymbol{x}}$

$$
\boldsymbol{A} \dot{\boldsymbol{x}}=\boldsymbol{F}
$$

where

$$
\begin{aligned}
& \dot{\boldsymbol{x}}_{(1 \times 108)}=\left[\begin{array}{llll}
\dot{\boldsymbol{q}}_{(1 \times 36)} & \dot{\boldsymbol{v}}_{(1 \times 36)} & \dot{\boldsymbol{\mu}}_{(1 \times 30)} & \dot{\boldsymbol{p}}_{(1 \times 6)}
\end{array}\right]^{\mathrm{T},} \\
& \boldsymbol{F}_{(1 \times 108)}=\left[\begin{array}{llll}
\boldsymbol{v}_{(1 \times 36)} & \boldsymbol{Q}_{E(1 \times 36)} & \left(\boldsymbol{Q}_{d}-2 \alpha \dot{\boldsymbol{\Phi}}-\beta^{2} \boldsymbol{\Phi}\right)_{(1 \times 30)} & \boldsymbol{h}_{1(\times 6)}
\end{array}\right]^{\mathrm{T}} \\
& \boldsymbol{A}_{(108 \times 108)}=\left[\begin{array}{cccc}
\boldsymbol{I}_{(36 \times 36)} & \boldsymbol{0}_{(36 \times 36)} & \boldsymbol{0}_{(30 \times 36)} & \boldsymbol{0}_{(6 \times 36)} \\
\boldsymbol{\boldsymbol { O }}_{(36 \times 36)} & \boldsymbol{M}_{(36 \times 36)} & \boldsymbol{\Phi}_{q(30 \times 36)}^{T} & \boldsymbol{0}_{(6 \times 36)} \\
\boldsymbol{0}_{(36 \times 30)} & \boldsymbol{\Phi}_{q(36 \times 30)} & \boldsymbol{0}_{(30 \times 30)} & \boldsymbol{0}_{(6 \times 30)} \\
\boldsymbol{0}_{(36 \times 6)} & \boldsymbol{0}_{(36 \times 6)} & \boldsymbol{0}_{(30 \times 6)} & \boldsymbol{I}_{(6 \times 6)}
\end{array}\right],
\end{aligned}
$$

and $\boldsymbol{M}$ is diagonal mass matrix; $\boldsymbol{\Phi}_{\mathrm{q}}$ is the Jacobian matrix of the system, which is referred to the matrix of partial derivatives of the position constraints with respect to the array of coordinates; $\boldsymbol{\Phi}$ is the vector of position constraint equations; $\boldsymbol{O}$ is a zero matrix; $\boldsymbol{I}$ is an identity matrix; $\boldsymbol{Q}_{\mathrm{E}}$ is 
a vector, containing external forces (weights of links and digging force); $\boldsymbol{Q}_{\mathrm{d}}$ is a vector, containing quadratic velocity terms; $\boldsymbol{h}$ is a vector, containing right hand sides of hydraulic equations for corresponding hydraulic cylinders; $\boldsymbol{p}$ is a vector, containing pressures in the hydraulic cylinder chambers. Also, it is accepted that $\dot{\boldsymbol{\mu}}=\lambda$.

The matrix equation Eq. (50) is computed at each simulation time step and solved for $\dot{\boldsymbol{q}}, \dot{\boldsymbol{v}}, \dot{\boldsymbol{\mu}}$ and $\dot{\boldsymbol{p}}$ using a standard matrix inversion routine, after which in each integration time step the state vector is integrated. This procedure is repeated until the final time is reached. As a result of the solution procedure, vectors of the generalized coordinates and velocities for each body together with the vector of Lagrange multipliers for each kinematical pair and pressures in the hydraulic cylinders are obtained.

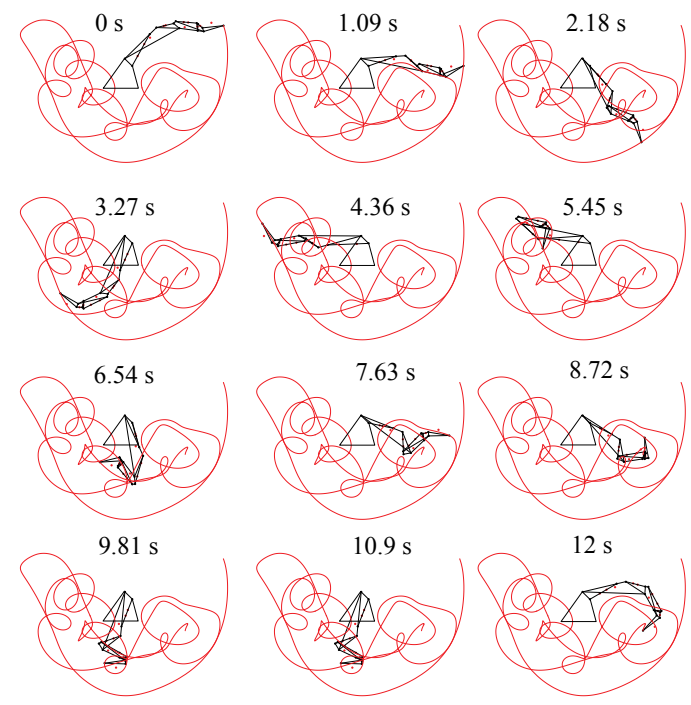

a) All elements have mass and inertial parameters

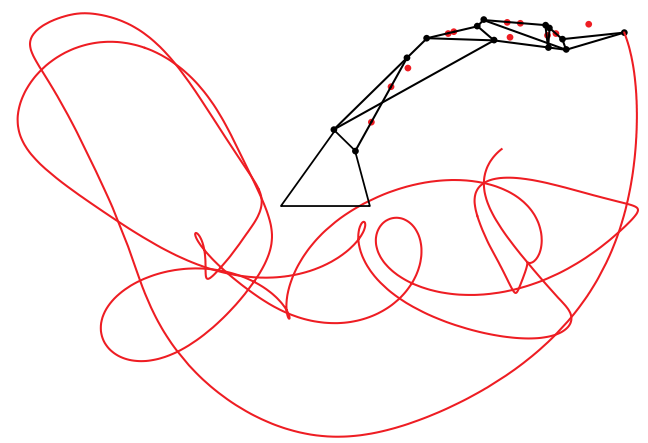

b) Only the boom, stick and bucket have mass and inertial parameters Figure 10 Trajectory of the bucket tip

\section{$5 \quad$ Numerical experiment and discussions}

The developed system of differential equations (50) is used to perform a numerical experiment with the inertial and geometrical data for the excavator CAT330DL. The overall mass of the excavator is $36000 \mathrm{~kg}$, mass of the boom $m_{1}=5027 \mathrm{~kg}$, mass of the stick is $m_{2}=3264 \mathrm{~kg}$, mass of the bucket is $m_{3}=2380 \mathrm{~kg}$, overall mass of the hydraulic cylinders and transmission linkages elements is $2750 \mathrm{~kg}$. As it was stated earlier, one of the main capabilities of the developed dynamical model is the inclusion of the mass and mass moments of inertia of the driving hydraulic cylinders and fourbar transmitting mechanism elements in the dynamical model. To demonstrate the effect of these additional mechanical elements on the movement of the system, a simulation of the system motion is carried out for the following two cases: 1) the motion of the mechanical system when all 12 mechanical elements have mass and inertial parameters; 2) the motion of the same mechanical system when the masses of the hydraulic cylinders elements and fourbar elements are ignored. In both cases the simulation is performed only under the action of the gravitational forces without considering the hydraulic circuits (free fall of the system). In Fig. 10a) a sequence of animation frames and trajectory of point L (bucket tip) is presented, obtained during the simulation of the system motion in the first case. In Fig. 10b) the trajectory of the point $\mathrm{L}$ is shown, obtained as a result of the simulation of the system motion in the second case. As one can see, in the two cases the motion of the system is different.

Fig. 11 gives the graphs of the kinetic -1 , potential - 2 and total energies -3 of the system. As expected, the total energy of the system is constant.

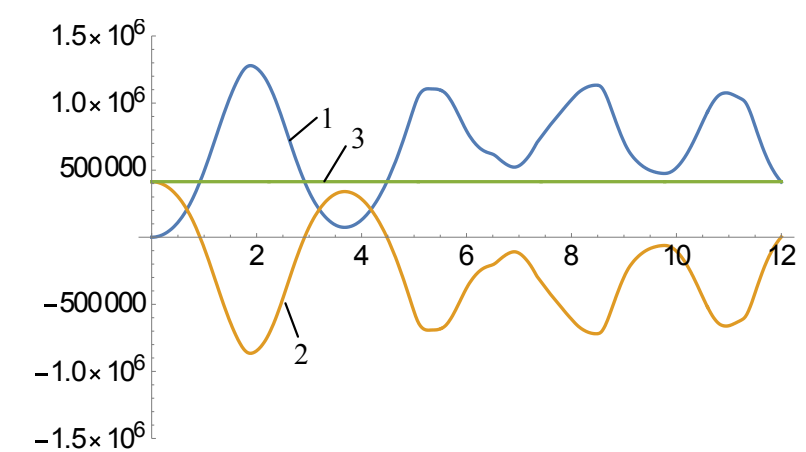

Figure 11 Kinetic, potential and total energies (in Joules) of the system as a function of time

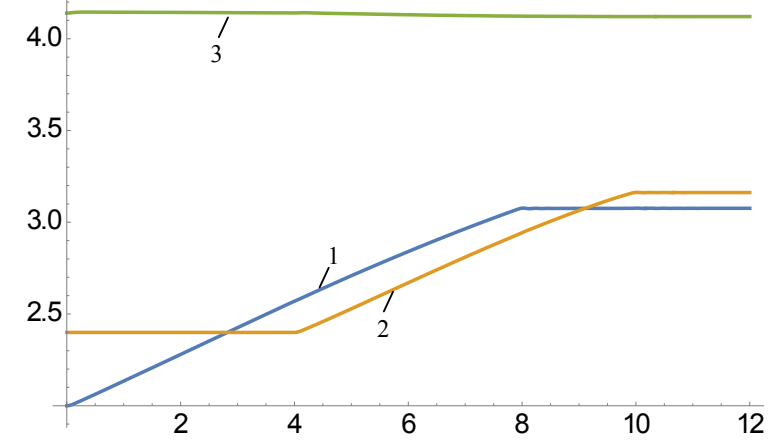

Figure 12 Extensions of the hydraulic cylinders (in meters) as a function of time (in seconds): 1) stick; 2) bucket; 3) boom

The graph of the energies, visual review and animation of the system motion are used for a verification of the developed dynamical model.

To demonstrate the capabilities of the developed dynamical model a numerical experiment is conducted and the dynamics of an excavator is studied during the digging operation. The digging task is performed by the stick and bucket motions which leads to the bucket filling along a digging trajectory. The length of the simulated digging task is 12 seconds. It consists of a stick hydraulic cylinder extension in the time interval from $0 \mathrm{~s}$ to $8 \mathrm{~s}$, followed by a bucket hydraulic cylinder extension in the 
time interval from $4 \mathrm{~s}$ to $10 \mathrm{~s}$ and during this time period the boom is fixed and serves as a supporting structure, see Fig. 12. The stick and bucket motions are performed by the corresponding hydraulic circuit valve opening $x_{v}^{i}(t)$ as a function of time according to Fig. 13.

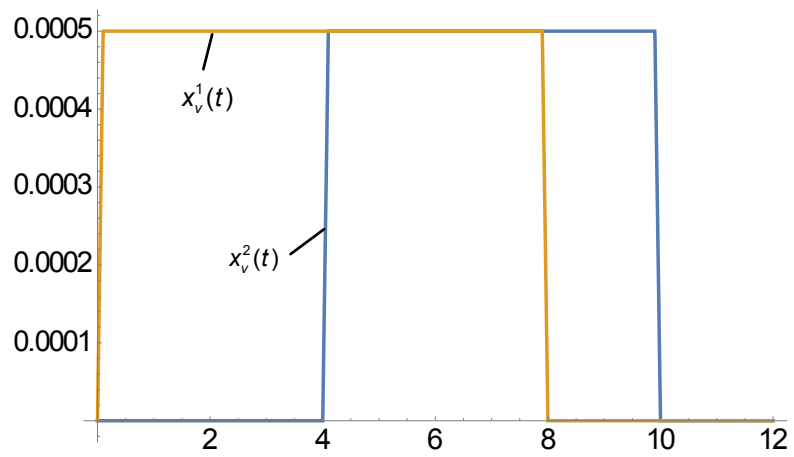

Figure 13 Valve openings $x_{v}^{1}(t)$ and $x_{v}^{2}(t)$ (in meters) as a function of time

Fig. 14 depicts a sequence of animation frames, consisting of geometrical configuration and bucket tip trajectory.
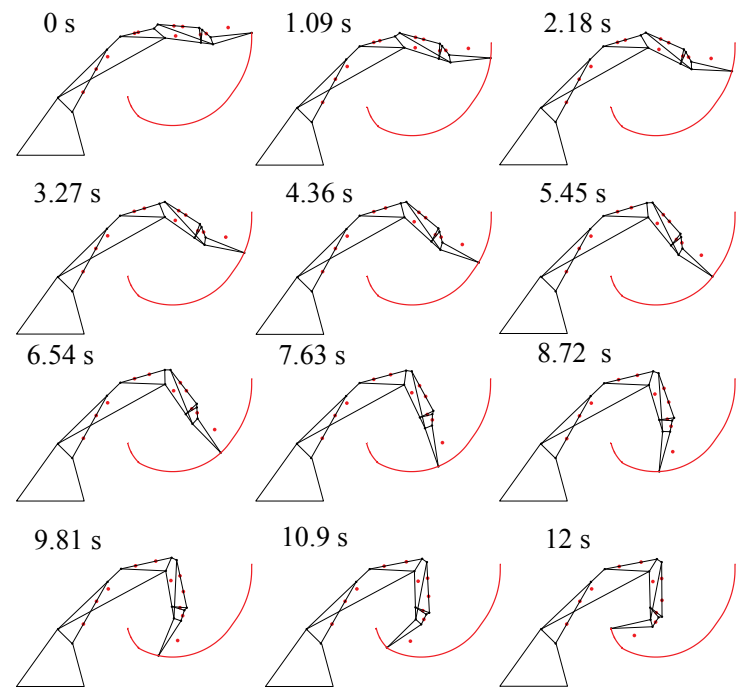

$10.9 \mathrm{~s}$

$12 \mathrm{~s}$
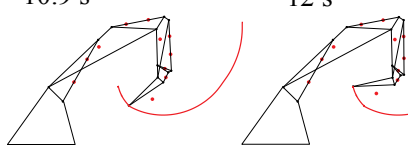

Figure 14 Sequence of animation frames from the simulation of the digging task

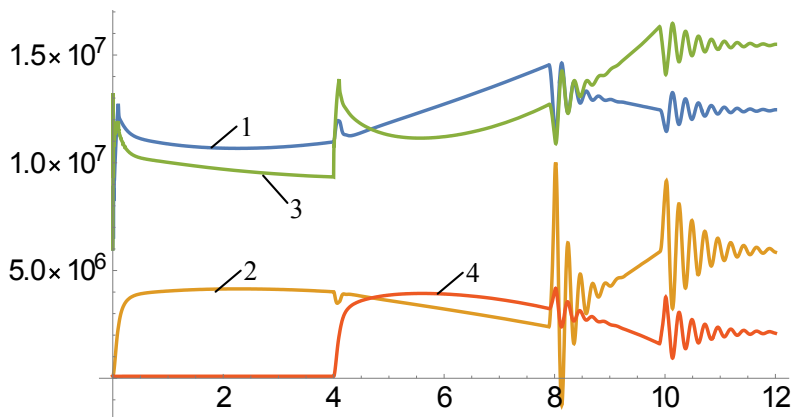

Figure 15 Pressures (in Pascals) in the hydraulic cylinders chambers: 1 and 2 - stick hydraulic cylinder; 3 and 4- bucket hydraulic cylinder

As a result of the integration of the dynamical equations, the following graphs are received: 1) Fig. 15 shows the time evolution of the pressures in the hydraulic cylinders chambers: 1 and 2 - of the stick, 3 and 4 - of the bucket; Fig. 16 depicts the linear velocities of the piston rods of the hydraulic cylinders: 1 - of the stick, 2-of the bucket, 3 - of the boom. In Fig. 17 the $x$ and $y$ components of the rotational joints reactions are shown: 1 and 2 - of the boom, 3 and 4 - of the stick, 5 and $6-$ of the bucket. Fig. 18 gives the $x-1$ and $y-2$ coordinates and rotation angle 3 of the base body 12. Finally, in Fig. 19 the velocity of the point L -3 and its projections onto the $x$ (curve 1) and $y$-axes (curve 2).

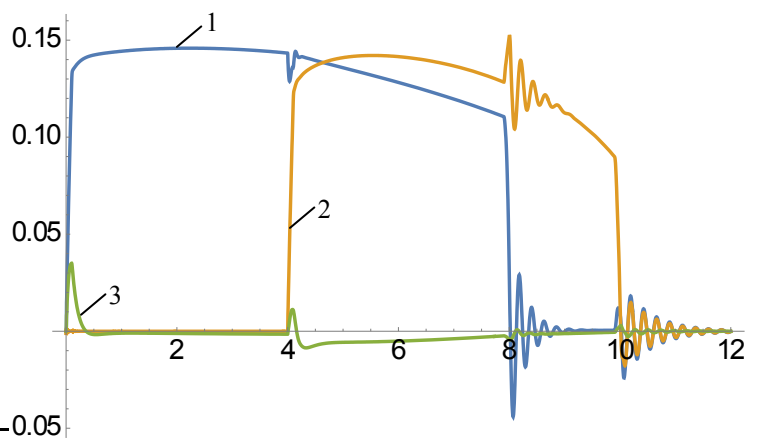

Figure 16 Hydraulic cylinders velocities (in m/s): 1 -stick, 2 - bucket, 3boom

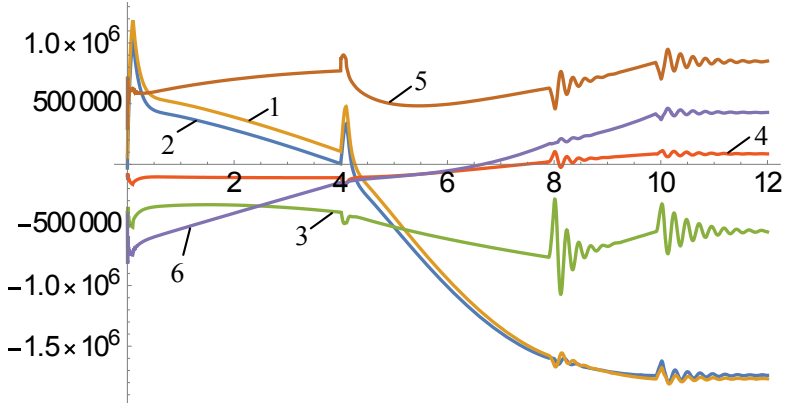

Figure $17 x$ and $y$ components of joints forces (in Newtons): 1 and 2 joint $A ; 3$ and 4 - joint $D ; 5$ and 6 - joint $G$

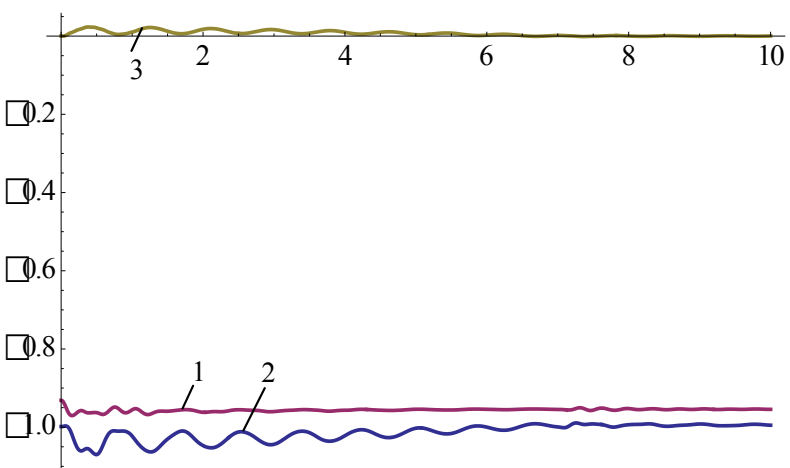

Figure 18 Position (in meters) of mass centre and rotation of the excavator base: 1 and $2-x$ and $y$ coordinates; 3 - rotation

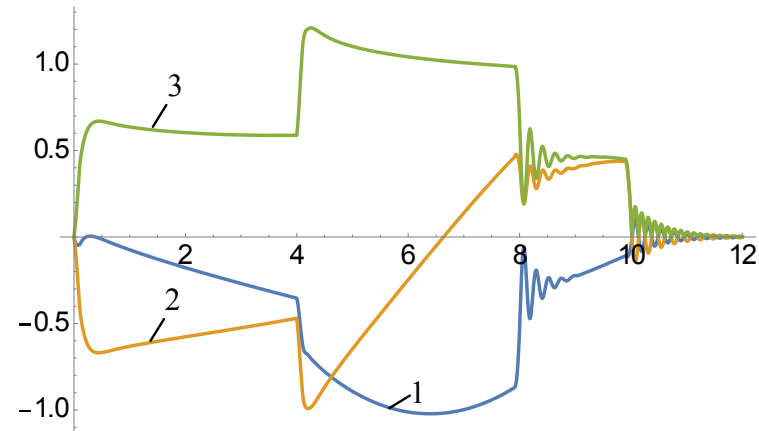

Figure 19 Velocities (in $\mathrm{m} / \mathrm{s}$ ) of the bucket tip - point $\mathrm{L} ; 1-\mathrm{x}$ projection; 2 - y projection; 3 - full velocity 
Validation of the developed model is one of the most difficult tasks. Inertial and geometrical parameters of the mechanical system can be easily obtained by the CAD model, but other parameters such as elasto-damping parameters of the tires, parameters of the hydraulic system and digging forces must be experimentally obtained.

\section{Conclusions}

Dynamical analysis is an essential part of the excavator design process. This process is highly iterative and a number of iterations are needed for achieving satisfactory design. The design of a system, containing subsystems from hydraulic and mechanical domains is difficult and the modelling technique must take into account their interaction when performing technological operations. The hydraulic actuator controlling the digging manipulator has its own dynamics due to the presence of inertial parameters of their elements and compressibility of the hydraulic oil. The internal forces which arise in the mechanical system during digging operations, pressures and flows in the hydraulic system are decisive for reliability and strength calculations of the excavator elements. That is why dynamical models suitable for investigation of the mechanical system during different parts of duty cycle have to be available. For precise design, strength and reliability calculations or simulation refined dynamical model of excavator manipulator is required.

This paper studied issues related to the development of a plane multibody mechanical model of a hydraulic excavator simultaneously containing an open kinematic chain and closed loops. The inclusion of large number of links increases the complexity of the dynamic model and numerical problems during the integration process of equations of motion.

The Lagrange multiplier technique plays a key role in the modelling of the constrained mechanical systems. In case of rigid body systems, this approach leads to a wellknown class of differential-algebraic equations. This approach is used for working out the dynamic equations of excavator motion in the case of performing transportation and digging operations. The excavator is considered as a rigid body system and detailed governing equations of the mechanical and hydraulic systems are presented. Such models can be used for developing training simulators, component sizing, and system design.

The performed verification and a typical digging task simulation demonstrated the applicability of the developed dynamical model for study of the excavator motion simulation. Simulation results of machine's response were provided. It was shown that the digging process considerably influences the mechanical and hydraulic system parameters. By simulation of various external influences such as impact or random forces one can explore mechanical and hydraulic systems response.

\section{Acknowledgement}

We acknowledge support by the German Research Foundation and the Open Access Publication Funds of Technische Universität Berlin.

\section{References}

[1] Marinković, Z.; Marinković, D.; Petrović, G.; Milić, P. Modeling and simulation of dynamic behavior of electric motor driven mechanisms. // Technical Gazette. 19, 4(2012), pp. 717-725.

[2] Jovanović, V.; Janošević, D.; Petrović, N. Experimental determination of bearing loads in rotating platform drive mechanisms of hydraulic excavators. Facta Universitatis Series: Mechanical Engineering. 12, 2(2014), pp. 157-169.

[3] Sun, Y.; Li, W.; Dong, D.; Mei, X.; Qiang, H. Dynamics analysis and active control of a floating crane. // Technical Gazette. 22, 6(2015), pp. 1383-1391. https://doi.org/10.17559/TV-20151026154842

[4] Grigorov, B.; Mitrev, R. Dynamic behavior of a hydraulic crane operating a freely suspended payload. // Journal of Zhejiang University - Science A (Appl Phys \& Eng). 18, 4(2017), pp. 268-281. https://doi.org/10.1631/jzus.A1600292

[5] Park, C; Lim, K. A Simulation Environment for Excavator Dynamics. Proceedings of the MSC.Software Virtual Product Development Conference / California, 2004. https://web.mscsoftware.com/events/vpd2004/n/proceeding s/pdfs/full papers/2004-070-FP park lim.pdf. (27.05.2017)

[6] Vaha, P. K.; Skibniewski, M. J. Dynamic Model of Excavator. // ASCE Journal of Aerospace Engineering. 6, 2 (1993), pp. 148-158. https://doi.org/10.1061/ (ASCE)0893-1321(1993)6:2(148)

[7] Koivo, A.; Thoma, M.; Kocaog-lan, E.; Andrade-Cetto, J. Modeling and control of excavator dynamics during digging operation. // Journal of Aerospace Eng., 9, 1(1996), pp. 10-18. https://doi.org/10.1061/(ASCE)0893-1321(1996)9:1(10)

[8] Vaha, P.; Skiebniewski, M.; Koivo, A. Kinematics and trajectory planning for robotic excavation. // Proceedings of the conference Preparing for Construction in the $21 \mathrm{st}$ Century: ASCE, 1991. pp. 787-793.

[9] Sleiman, H.; Mélin, C.; Vidolov, B. A Variant of Time Delay Control. // Proceedings of the $7^{\text {th }}$ IMACS World Congress Scientific Computation on Applied Mathematics and Simulation, 2005, pp. 1-6.

[10] Budny, E.; Chlosta, M.; Gutkowski, W. Load-independent control of a hydraulic excavator. Automation in Construction. // 12, 3(2003), pp. 245-254. https://doi.org/ 10.1016/S0926-5805(02)00088-2

[11] Liu, Y.; Hasan, M.; Yu, H. Modelling and Remote Control of an Excavator. // International Journal of Automation and Computing. 7, 3(2010), pp. 349-358. https://doi.org/10.1007/s11633-010-0514-8

[12] Gudarzi, M. Reliable robust controller for half-car active suspension systems based on human-body dynamics. // Facta Universitatis, Series: Mechanical Engineering. 14, 2(2016), pp. 121-134. https://doi.org/10.22190/FUME1602121G

[13] Janssen, B.; Nievelstein, M. Multi-loop Linkage Dynamics via Geometric Methods: A Case Study on a RH200 Hydraulic Excavator / Technische Universiteit Eindhoven, Eindhoven, 2005.

[14] Wszolek, G. Vibration analysis of the excavator model in GRAFSIM program on the basis of a block diagram method. // Journal of Materials Processing Technology. 157-158(2004), pp. 268-273. https://doi.org/10.1016/j.jmatprotec. 2004.09.041

[15] Stefanović-Marinović, J.; Troha, S.; Milovančević, M. An application of multicriteria optimization to the two-carrier two-speed planetary gear trains. // Facta Universitatis, Series: Mechanical Engineering. 15, 1(2017), pp. 85-95. https://doi.org/10.22190/FUME160307002s

[16] Luengo, O; Singh, S; Cannon, H. Modeling and Identification of Soil-tool Interaction in Automated Excavation. Proceedings of the International Conference on 
Intelligent Robots and Systems / Victoria, B.C., Canada, 1998. https://doi.org/10.1109//ROS.1998.724873

[17] Towarek, Z. Dynamics of a single-bucket excavator on a deformable soil foundation during the digging of ground. // International Journal of Mechanical Sciences. 45, 67(2003), pp. 1053-1076. https://doi.org/10.1016/j.jmecsci.2003.09.004

[18] Coetzee, C.; Basson, A.; Vermeer, P. Discrete and continuum modelling of excavator bucket filling. // Journal of Terramechanics. 44, 2(2007), pp. 177-186. https://doi.org/10.1016/j.jterra.2006.07.001

[19] Ericsson, A.; Slattengren, J. A Model for predicting digging forces when working in grave or other granulated material. // Proceedings of the 15th European ADAMS Users' Conference / Rome, Italy, 2000. http://web.mscsoftware.com/support/library/conf/adams/eur o/2000/Volvo_Predicting_Digging.pdf. (27.05.2017)

[20] Akyeampong. J.; Udoka, S., Park, H. A Hydraulic Excavator Augmented Reality Simulator for Operator Training. // Proceedings of the International Conference on Industrial Engineering and Operations Management Istanbul / Turkey, 2012.

[21] Zweiri, Y.; Seneviratne, L.; Althoefer, K. Modelling and control of an unmanned excavator vehicle. // Proceedings of the Institution of Mechanical Engineers. Part I Journal of systems and Control Engineering. 217, 4(2003), pp. 259274. https://doi.org/10.1177/095965180321700402

[22] Malaguti, F.; Zaghi, S. Force sensor by driving hydraulic cylinders: identification of inertial parameters and tests. // Proceedings of the 19th ISARC / Washington, U.S.A., 2002, pp.431-436.

[23] Mitrev, R.; Savov, S. A theoretical-experimental approach for elasto-damping parameters estimation of cone inertial crusher mounting. // Facta Universitatis, Series: Mechanical Engineering. 15, 1(2017), pp. 73-83. https://doi.org/10.22190/FUME161013006M

[24] Frimpong, S.; Hu, Y.; Inyang, H. Dynamic Modeling of Hydraulic Shovel Excavators for Geomaterials. // International Journal of Geomechanics. 8, 1(2008), pp. 2029. https://doi.org/10.1061/(ASCE)1532-3641(2008)8:1(20)

[25] Papadopoulos, E.; Sarkar, S. The dynamics of an articulated forestry machine and its applications. Proceedings of the IEEE International Conference on Robotics and Automation / Albuquerque, New Mexico, 1997, pp. 323328. https://doi.org/10.1109/ ROBOT.1997.620058

[26] Sarata, S.; Sato, K.; Yuta, S. Motion control system for autonomous wheel loader operation. Proceeding of the International Symposium on Mine Mechanization and Automation / Golden, CO, USA, 1995, pp. 155-165.

[27] Beater, P.; Otter, M. Multi-Domain Simulation: Mechanics and Hydraulics of an Excavator. // Proceedings of the $3^{\text {rd }}$ International Modelica Conference / Linköping, 2003.

[28] Solazzi, L. Design of aluminium boom and arm for an excavator. // Journal of Terramechanics. 47, 4(2010), pp. 201-207. https://doi.org/10.1016/j.jterra.2010.03.002

[29] Serra, M. Optimum design of thin-walled closed crosssections: a numerical approach. // Computers and Structures. 83, 4-5(2005), pp. 297-302. DOI: 10.1016/ j.compstruc.2004.10.004

[30] Imanishi, E.; Nanjo, T.; Hirooka, E.; Sugano, N. Fast simulation on flexible multibody dynamics using domain decomposition technique. // Journal of system design and dynamics. 1, 3(2007), pp. 387-397. https://doi.org/10.1299/jsdd.1.387

[31] Linjama, M.; Virvalo, T. Low-order dynamic model for flexible hydraulic cranes. // Proceedings of the Institution of Mechanical Engineers, Part I: Journal of Systems and Control Engineering. 213, 1(1999), pp. 11-22. https://doi.org/10.1243/ 0959651991540340
[32] Hiller, M. Modelling, simulation and control design for large and heavy manipulators. // Robotics and Autonomous Systems. 19, 2(1996), pp. 167-177. https://doi.org/10.1016/S0921-8890(96)00044-9

[33] Lin, G.C.; Wang, D.M.; Xu L.J.; Gao, S. The analytical dynamic model of six-DOF industrial robotic manipulators of containing closed chain. // Mechanism and Machine Theory 40, 4(2005), pp. 385-393. https://doi.org/10.1016/ j.mechmachtheory. 2004.05.012

[34] Fox, B.; Jennings, L.; Zomaya, A. On the modeling of actuator dynamics and the computation of prescribed trajectories. // Computers and structures. 80, 7-8(2002), pp. 605-614.

[35] Nguyen, H. Robust low level control of robotic excavation. $\mathrm{PhD}$ thesis. Australian centre for field robotics, The University of Sidney, Sidney, 2000.

[36] Prabhu, S.M.; Model-Based Design for Off-Highway Machine Systems Development. // Proceedings of SAE Commercial Vehicle Engineering Congress \& Exhibition, 2007. https://www.mathworks.com/tagteam/44719_Prabhu 2007-01-4248_Final.pdf (27.05.2017)

[37] Shabana A. Computational dynamics, $3^{\text {rd }}$ edition, Wiley, 2009.

[38] Tafazoli, S.; Lawrence, P. D.; Salcudean, S. E., Chan, D.; Bachmann, S.; de Silva, C. Parameter Estimation and actuator friction analysis for a mini excavator. // Proceedings of 1996 IEEE International Conference on Robotics and Automation / Minneapolis, Minnesota, USA, 1996. https://doi.org/10.1109/ROBOT.1996.503798

[39] Patel, P.; Prajapati, J.; Gadhvi, B. An excavation force calculations and applications: an analytical approach. // International Journal of Engineering Science and Technology. 3, 5(2011), pp.3831-3837.

[40] Alekseeva, T.; Artemev, K.; Voitsekhouskii, R.; Ulyanov, N. Machines for earthmoving work, theory and calculations. Amerind Publishing Co., New Delhi, India, 1985.

[41] Zelenin, A. N.; Balovnev, V. I.; Kerov, I. P. Machines for Moving the Earth. Amerind Publishing, New Delhi, India, 1985.

[42] Vetrov, Y. Cutting of soils by earthmoving machines. Mashinostroenie, Moskow, 1970.

[43] Watton J. Fundamentals of fluid power control. Cambridge University Press, 2009. https://doi.org/10.1017/CB09781139175241

\section{Authors' addresses}

Rosen Mitrev, Assoc. Prof., PhD

Technical University-Sofia, Faculty of Mechanical Engineering Kliment Ohridski blvd. 14, Sofia, Bulgaria

E-mail: rosenm@tu-sofia.bg

Dragoslav Janošević, Prof., PhD

University of Niš, Faculty of Mechanical Engineering

A. Medvedeva 14, 18000 Niš, Serbia

E-mail: janos@masfak.ni.ac.rs

Dragan Marinković, Assoc. Prof., PhD

Corresponding author

Technische Universität Berlin

Institut für Mechanik, FG Strukturmechanik und

Strukturberechnung

Straße des 17. Juni 135, 10623 Berlin, Germany

E-mail: dragan.marinkovic@tu-berlin.de 